\title{
The Effect of Organizational Silence on Burnout: A Field Study on Workers at Jordanian Five Star Hotels
}

\author{
Mahmoud Ali Mohammed Al-Rousan ${ }^{1} \&$ Muthana Mohammad Omoush ${ }^{2}$ \\ ${ }^{1}$ Department of Management Information Systems, College of Business Administration, Ajloun National University, \\ Ajloun, Jordan \\ ${ }^{2}$ Department of Tourism Management, Irbid National University, Irbid, Jordan \\ Correspondence: Mahmoud Ali Mohammed Al-Rousan, Department of Management Information Systems, College \\ of Business Administration, Ajloun National University, Ajloun, Jordan.
}

Received: April 8, 2018

doi:10.5430/jms.v9n3p114
Accepted: July 29, 2018

Online Published: August 20, 2018

URL: https://doi.org/10.5430/jms.v9n3p114

\begin{abstract}
The study aims at determining the reality of the organizational silence for workers at the Jordanian five star hotels, investigation of their organizational silence level, study the relation between it and the effect ofthe organizational silence on burnout. A sample of workers in ten operating hotels in Amman was selected to be analyzed on (161) questionnaires. It was found out that all the indicators related to the reasons for organizational silence were at an average degree, theburnout level was at an average degree, there is a relation between organizational silence as a whole and each aspect of organizational silence and there is an effect of organizational silence reasons on burnout. Some recommendations are presented. The most of which are: the need for effective communication between the departments and workers through flexible organizational structures, establishing the democratic practices and providing appropriate work conditions.
\end{abstract}

Keywords: organizational silence, Jordanian five star hotels, tourism

\section{Introduction}

The environment in which the individual works in organizations made him subject to many challenges, which werereflected on his psyche and purity of his mind. These pressures vary from one person to another. As aresponse, the individuals resort to regression and silence. This silence has many causes, including reasons related to the organization's internal environment (Organizational climate), the individual himself in addition to the social aspects. Further, the deeper the organizational silence, the more negative trends and depletion of feelings will be generated, leading to burnout.

\subsection{Problem of the Study}

All workers in the organizations suffer from a certain level of psychological stress resulting from the nature of work, conditions of work, method and manner of its management, nature of the clients and different environmental conditions. We find that, by virtue ofdealing with a wide range of public, the multiplicity of services provided, multiple means of control, work pressure and the prevailing patterns of leadership,the hotels make the workers feel pressure,tension and fatigue. Thus, the current research is an attempt to find out the answer to three questions:

1. What are the reasons behind the workers' silence?

2. What are the levels of burnout?

3. What is the nature of relationship and the effect between silence of workers and burnout?

\subsection{Significance of the Study}

The significance of the study is highlighted by discussing two issues: organizational silence and burnout, which are of great importance in modern administrative thought, as they were not adequately addressed in the Arabic literature according to researchers' knowledge. The field of the study is Jordanian hotels, which is one of the sectors that have a large economic effectat the level of national economy, investors or common individuals. 


\subsection{Objectives of the Study}

The study aims to achieve a set of objectives as follows:

1. Explaining the concepts of organizational silence and burnout.

2. Identifyingthe reasons for organizational silence of workers in Jordanian hotels.

3. Identifying the levels of burnout of workers in these hotels.

4. Showing the nature of the relationship and effect between reasons for organizational silence and burnout.

1.4 Hypotheses of the Study

\subsubsection{The First Main Hypothesis}

There is a statistically significant relationship between reasons for organizational silence combined and burnout.The following sub-hypotheses emerge:

1. There is a statistically significant relationship between reasons for organizational silence combined and emotional exhaustion.

2. There is a statistically significant relationship between reasons for organizationalsilence combined and depersonalization.

3. There is a statistically significant relationship between reasons for organizational silence combined and Low personal accomplishment.

\subsubsection{The Second Main Hypothesis}

There is an effect of the reasons for organizational silence combined on burnout. The following sub-hypotheses emerge:

1. There is an effect of the reasons for organizational silence combined on emotional exhaustion.

2. There is an effectof the reasons for organizational silence combined on depersonalization.

3. There is an effect of the reasons for organizational silence combined on Low personal accomplishment.

\subsection{The Study Population and Sample}

Five star hotels in Amman were chosen as a field of the study. The survey questionnaire was distributed to a random sample of (200) respondents, of which (183) were returned and the analysis was conducted on (161) questionnaires with full specifications.

\subsection{Methods of Data Collection}

The two researchers went in two directions. The first direction towards the books and studies that dealt with variables of the study (organizational silence and burnout) in order to establish the theoretical aspect, and the second towards adapting the questionnaire that was used by MeldaHarbioglus (2014), HasanKaraca (2013) and Aboud\&Hussien, (2016).For the special variable (organizational silence) and the burnoutindex (Maslach\&Leiter, 1997), it was used by (Al-Tlaa' 2015). The questionnaire was used to gather initial data from the field.

\section{Review of Literature}

The purpose of the study by Aboud\&Hussien, (2016) is to study the affective relationship between the reasons for organizational silence and performance of the workers. The study was conducted on the staff of Babylon University / Iraq, randomly selected on a sample of (100) individuals. It was found that there is a clear negative effect of the reasons for silence on performance indicators.

The study by (Al Wahibi, 2014) aims to identify the most important factors that cause the organizational silence for the employees of government departments in Al Qusaim region, determine the differences in the organizational climate in these departments and finally reach the effect of organizational climate'sdimensionsjointly and separately on preference of organizational silence for theemployees. It was found that there is an effect of good values, the flow of communication and the view of the human element jointly and separately on organizational silence.

In Orhan et al (2013), the researchers attempted to understand the relationship between organizational silence and organizational citizenship behavior. Due to many threats to organizations within a competitive business environment, the study found a strong and negative relationship between the operation system and organizational citizenship. This means that if employees are not allowed to express their ideas about organizational work, this will negatively affect the level oforganizational citizenship behavior. 
The study of Shar et al, 2015 aims to explain the relationship between dimensions of organizational climate and commitment among theemployees of the humanities and administrative science faculties, where the sample was divided into professors and staff members. A relationship was found between organizational climate and organizational silence. It was found that organizational silence is stronger for the staff members and the level of organizational commitment is higher among professors.

Woodhead (2014) examined work pressures, social support and three variables of burnout (occupational exhaustion, depersonalization and Low personal accomplishment). The study was conducted on 250 nursing staff. The results showed that there is a correlation between work pressure with occupational exhaustion, depersonalization and low level of achievement and that social support reduces the burnout. The study stresses the need to focus on factors of work pressures andsocial support.

\subsection{Conceptual Framework}

\subsubsection{First: Organizational Silence}

\section{The Concept of Organizational Silence}

It is this situation where the employee abstains from saying a piece of information that may be to the interest of the organization intentionally or unintentionally (Subra, 2009, 5). It is the orientation of subordinates in organizations to avoid providing information, proposals or news about problems to their bosses as they are afraid of any negative reactions or unacceptable results that may emerge (Al Wahibi, 372, 2014). (Aboud\& Hussein 2016, 238) consideredorganizational silence is reluctance of the employee to talk about issues that occur at work for fear of misinterpretation by his direct supervisor, and therefore they may negatively affect the relations between him and his coworkers. Based on the above, we find that there are clear commonalities between those who are exposed to the term in terms of avoiding talk about work, reluctance and fear of presenting visions, perceptions and information about work or coworkers so as not to be misunderstood.

Tutay $(2010,200)$ argues that organizational silence is not an individual behavior, but it permeates the organization as a whole. It is the general attitude of workers towards the issues that occur within the organization. Organizational silence leads to negative results, the most important of which is obstructing the process of development and organizational change, reluctance in participation in the change process, absence of efficiency, poor performance (Paul et.al, 2005, 39), dissatisfaction among the organization's personnel, low individual and organizational performance (Bagheri\&Nik, 2012, 36).As for the sources of organizational silence, Al Wahaibi $(372,2014)$ classified them as stressful job sources such as lack of social support, ambiguity of roles, increased workloads, and personal and psychological sources such as sex, education level and age.

The reasons for organizational silence are attributed to organizational biases, negative reactions from management, lack of objectivity, lack of trust, personality characteristics of managers and their limited experience (Erglu, 2011, 101). The reasons can be explained in five headings: the first are administrative and organizational reasons, as the individuals resort to organizational silence for fear of negative reactions leading to many problems related to decision-making, organizational efficiency and poor performance (Rosemary, 2003, 9). The second is the fear of social isolation, astalking about work problems leads to damage in social relations within the organization (Morrison \&Millikon, 2003, 1460). The third is limited experience, as the previous experiences by the individuals regarding the negative results they encountered make them avoid problems or discussing them with their coworkers or superiors, despite their awareness of the importance of standing up early. The fourth reason is the fear of damaging the relations, as the fear of losing relations with colleagues who are valuable is hard to concede and the fifth and last reason is work relatedconcerns, as fear of losing a promotion and being abused.

As for the stages of organizational silence, Pideriteand Ashford $(2003,15)$ mentioned that there are four stages, the first is the stage of introspection, when there is an incompatibility between what is expected and reality. The second is depression, andhere the level ofwork satisfaction gradually decreases and the performance decreases. The third is separation, and here the psychological withdrawalbegins, which means chronic exhaustion and ill health resulting in silence, while the last stageis known as the stage of communication, so that the individual'sthinking is disturbed by the hardships, and here continuous thinking to quit work emerges.

\subsubsection{Second: Burnout}

It is a form of stress that includes negative feelings and reactions towards the others,oneself and his achievement (Yusuf, 2007, 40). It is a set of symptoms that affect workers as a result of work pressures and dealing with the beneficiaries leading to their feelings of emotional exhaustion, depersonalization and low achievementlevel (Tlaa, 2015, 189). Pines \&arouonson (Jaber, 2007,131) sees it as a state of physical, mental, nervous and emotional stress, 
and it results from working with people and interacting with them for a long time in situations that need to exert an doubled emotional effort.

Burnout occurs when there is no correlation between nature of work and nature of the person involved in performance of the work. The greater the disparity between these two environments, the greater the burnoutwill be for the worker in his place of work (Qarni, 2004, 10).Maslak determined three dimensions of burnout. The first is emotional exhaustion, which usually arises because of the increased psychological, emotional and biological demands on those persons responsible for serving others (Mar cell a, 2007, 26). The second is depersonalization, which is loss of the human element or person in dealing with individuals, as the worker is characterized with roughness, pessimism, increasing criticism and blaming the coworkers and beneficiaries (Adais, 2012, 44). The third is the feeling of Low personal accomplishment. Here the worker becomes dissatisfied and is unconvinced with his professional performance and achievements (Maslash\&Leiter, 1997, 87).

In the view of (Angel et al., 2003, 49), the changes in the events of life, work pressures, poor social support, feeling of failure, office work, role and ambiguity of roles are causes of burnout. Symptoms of burnoutinclude physical exhaustion, frequent absence, chronic fatigue and boredom, impatience, headache and resistance to change (Weimer, 2010, 46).

\section{The Practical Side}

\subsection{Descriptive Analysis of Study Variables}

Table 1 indicates the arithmetic meanvalues. It is clear that arithmetic meansranged from (368) for the variable of lack of experience and (3.81) for the variable of social isolationconcerns. All arithmetic means for the five variables in relation to reasons for organizational silence are within the average degree, which means that the study sample is fully aware of availability of these dimensions.

Table 1. Reasons for organizational silence for workers in Jordanian commercial banks

\begin{tabular}{ll}
\hline Reasons fororganizational silence & The Arithmetic Mean \\
\hline Administrative and organizational reasons & 3.72 \\
\hline Lack of experience & 3.68 \\
\hline Concerns related to work & 3.77 \\
\hline Concerns from social isolation & 3.81 \\
\hline Fear of damages from work relations & 3.73 \\
\hline
\end{tabular}

The included in Table 2 refer toburnout indicators and all arithmetic means were at average degree. The highest one is at emotional exhaustion at a mean of 3.75 and the lowest is at personal achievement with a mean of 2.38. This means that workers in Jordanian commercial banks suffer from emotional burnout in an average degree.

The study found many of the results, where it turned out that the most important factors that lead to silence the regulatory descending order is the directors fear from feedback, lack of communication skills, lack of top management support, isolation, fear of adverse reactions to any suggestions or criticisms presented by staff

Table 2. Level of burnout for workers in Jordanian commercial banks

\begin{tabular}{ll}
\hline The Indicator & The Arithmetic Mean \\
\hline Emotional exhaustion & 3.75 \\
\hline Depersonalization & 3.48 \\
\hline Low personal accomplishment & 2.38 \\
\hline
\end{tabular}

\subsection{Testing the Hypotheses}

First: testing the first main hypothesis and its secondary hypotheses. The data included in Table 3 show the following: 
1. When the value of correlation coefficient $(0.503)$ is tested by $(t)$, it was found that the calculated(t) value (3.401) when compared to tabulated ( $\mathrm{t}$ ) value (2.44) under significance level $(0.01)$ show that the calculated ( $\mathrm{t}$ ) value is bigger than the tabulated value. This means that there is a significant correlation between the independent variable (reasons for organizational silence) and the adopted variable (emotional exhaustion) for one of the burnout indicators thus provingthat the first secondary hypothesis is correct.

2. When the value of correlation coefficient $(0.280)$ is tested by $(t)$, it was found that the calculated ( $t)$ value (2.273) is bigger than tabulated (t) value (1.691) under significance level (0.05). This means that there is a significant correlation between the independent variable (organizational silence) and the adopted variable (depersonalization) as one indicator of burnout. Accordingly, the second secondary hypothesis can be accepted.

3. When the value of correlation coefficient $(0.524)$ is tested by $(t)$, it was found that the calculated ( $t$ ) value (3.742) is bigger than tabulated $(t)$ value (2.44) under significance level $(0.01)$. This means that there is a significant correlation between the independent variable (organizational silence) and the adopted variable (Low personal accomplishment) as one indicator of burnout. Accordingly, the third secondary hypothesis can be accepted.

4. When the value of correlation coefficient $(0.503)$ is tested by $(t)$, it was found that the calculated ( $t$ ) value (3.540) is bigger than tabulated $(\mathrm{t})$ value (2.44) under significance level $(0.01)$. This means that there is a significant correlation between the independent variable (organizational silence) and the adopted variable (burnout) as one indicator of burnout. Accordingly, the first main hypothesis can be accepted.

Table 3. Correlations between organizational silence and burnout

\begin{tabular}{lllll}
\hline Adopted Variables & $\begin{array}{l}\text { Emotional } \\
\text { Exhaustion }\end{array}$ & depersonalization & $\begin{array}{l}\text { Low personal } \\
\text { accomplishment }\end{array}$ & Burnout \\
\hline Organizational Silence & $* * 0.488$ & $* 0.350$ & $* * 0.524$ & $* * 0.503$ \\
\cline { 2 - 5 } & 3.401 & 2.273 & 3.742 & 3.540 \\
\hline
\end{tabular}

* (t) value under significance level (0.05) is (1.691)

* $(\mathrm{t})$ value under significance level $(0.01)$ is $(2.44)$

\subsection{Second the Effect of Organizational Silence on Burnout}

In order to test the validity of the second hypothesis and its sub-hypotheses, simple regression analysis was used and its results are shown in Table 4. It shows that there is a statistically significant positive effectof organizational silence on burnout. The calculated (F) value of (34.3), which is bigger than its tabulated value (1.08) at freedom degree (1.40) within significance level $(0.05)$ at confidence degree $(95 \%)$ shows that the regression is significant. The value of regression coefficient $\left(\mathrm{R}^{2}\right)$ indicates that the explanatory possibility of the regression equation reached $(91.9 \%)$, which is a high percentage indicating that (91.9) of the changes involved in burnout are explained by organizational silence. As for the remaining percentage $(8.1 \%)$, its interpretation is due to other random variables that are not included in the study model. By observing the value of $\beta$ coefficient, i.e. the value of partial regression coefficient, and (t) test, we note that it reached (1.606), which is a significant value because the calculated (F) value of (34.03) is bigger than the tabulated value of (4.08) at freedomdegree (1.40) within significancelevel (0.05) i.e.at confidence level $(95 \%)$. Results show the importance of organizational silence and its clear effect on aspects of burnout forworkers in Jordanian hotels.

In order to give detailed indicators of the nature of the effect of organizational silence on burnout in emotional exhaustion element, this was shown by the value of $(\beta)$ coefficient of $(0.342)$ which is a significant value that supports the value of $(\mathrm{F})$, as its calculated value is (16.047) which is (4.08) bigger than the tabulated value (4.08) at freedom degree (1.40) within significancelevel (0.05) i.e.at confidence level (95\%). This can be explained by the fact that whenever there is an increase in organizational silencelevels, it will affect emotional exhaustion more and thus prove the validity of the first hypothesis.

As for the effect of organizational silence at the axis of depersonalization, the value of beta coefficient $(\beta)$ reached (0.482), which is a significant value that is supported by the $(\mathrm{F})$ value, as its calculated value is (50.592), which is greater than its tabulated value of (4.08) at freedom degree (1.40) within significancelevel (0.05) i.e.at confidence 
level (95\%). This can be explained by the fact that high organizational silencelevel will affect depersonalization among workers in Jordanian hotels and thus prove the validity of the second hypothesis.

As for the effect of organizational silence on Low personal accomplishment, this is indicated by the value of beta ( $\beta$ ) coefficient of (0.347), which is a significant value that supports the $(\mathrm{F})$ value, asits calculated value (8.793) is bigger than its tabulated value of (4.08) at freedom degree (1.40) within significancelevel (0.05) i.e.at confidence level (95\%). This can be explained that increasing organizational silence level affects personal achievement, thus validating the third hypothesis.

Based on the above, the second main hypothesis "reasons for organizational silence combined have an effecton burnout" can be accepted.

Table 4. The Effect of organizational silence on dimensions of burnout

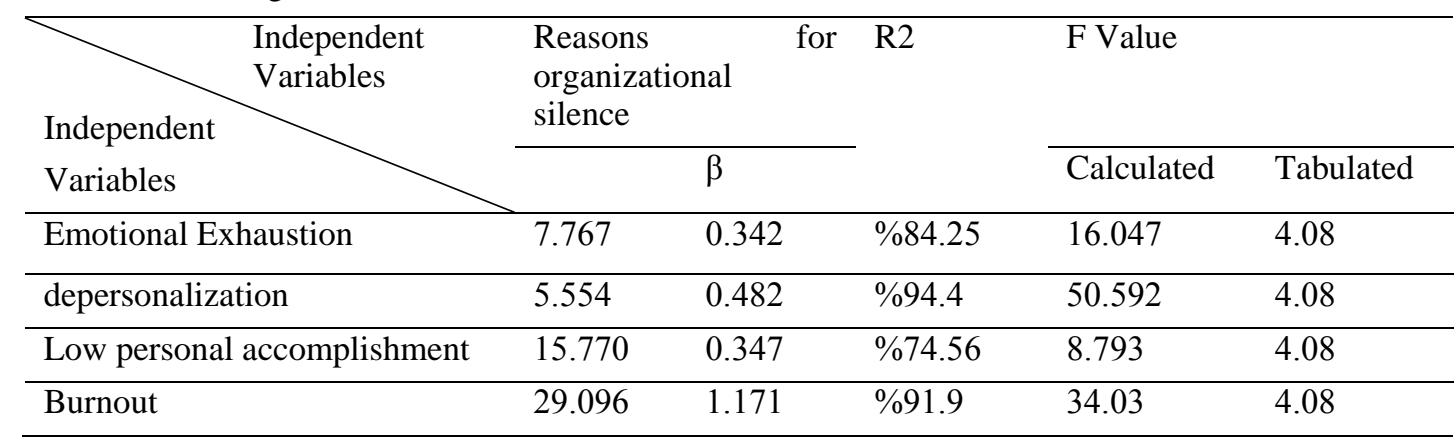

$\mathrm{P} \leq 0.05 ;$ d.f (1.40)

\section{Conclusions}

1- There is a difference in the definition of organizational silence and burnout concepts in the literature dealing with these two concepts.

2- There are different reasons for organizational silence and burnout according to the directions of authors and researchers.

3- Workers in Jordanian hotels are aware of the reasons for the organizational silence in their work environment.

4- Workers in Jordanian hotels suffer from burnout at an average degree.

5- The relationship between the reasons for organizational silence combined with burnout in general and with each of the three burnout elements.

6- Reasons for organizational silence combined affect each sub-variable of burnout.

\section{Recommendations}

First: Working to reduce organizational silence level to its minimum limits through:

1- Working to increase confidence between the employees and management.

2- Adopting flexible organizational structures to increase communication between management and employees vertically and horizontally.

3- Spreading the democratic atmosphere and encouraging employees to talk aboutwork problems away from the atmosphere of exclusion and retaliation.

Second: Burnout is a reality that must be managed, working to reduce its level and addressing its reasons through:

1- Mitigation of work pressures.

2- Allowing a space of freedom to act and take appropriate action by the workers.

3- Increasing positive reinforcement through an appropriate incentive system.

4- Participation of employees in personal events and improving social atmospheres.

5- Working to bring about change in the workplace, its nature, procedures and environment.

6- Workingto integrate workers in their work (organizational normalization). 


\section{References}

Aboud, Z., \& Hussain, Z. N. (2016). Reasons for Organizational Silence and their Effect on Performance of Workers. Babylon University Journal / Applied Sciences, 24(1).

Adais, A. (2012). The Relationship between Application of Information Technology and Burnout in the Palestinian Telecommunications Company from the Employees' Perspective - A Case Study. Unpublished Master Thesis, Al Khalil University - Palestine.

Al-Qarni, A. S. (2004). Media and Psychological Burnout, a Study on WorkPressure Levels in Media Institutions in Kingdom of Saudi Arabia. King Saud University, Riyadh, Kingdom of Saudi Arabia.

Al-Talaa, S. A. (2015). The reality of Burnout and its Reasons among the workers in the Electricity Distribution Company of Gaza Governorates. Al-Azhar University Journal, 17(2a), Gaza.

Al-Wahibi, A. M. (2014). The Effect of Climate in the Government Departments in Al Qusaim Region on Organizational Silence. Jordanian Journal of Business Administration, 10(3).

Eroglu. H., Adiguze, O., \& Ozturk, U. (2011). Dilemma of silence vorte and commitment: Relationship between Employee silence and organizational commitment. The Journal of Faculty of Economics and Administrative Science, 16(2). Suleymandemirel University.

Jaber, R. F. (2007). A study of Evaluation of Psychological Burnout of the Trainer. Al-Aqsa Magazine, 11(1). Al-Aqsa University, Gaza.

Marcella, W. (2007). Follow This Tips to prevent professional, 22(4).

Maslach, C., \& Leiter, P. (1997). The Truth about Burnout: How Organizations cause personal stress and what to do about it. San Francisco: Jossey - Bass Publishers.

Milliken, F. J., Morrison, E. W., \& Hewlin, P. F. (2003). An exploratory study of Employee silence: issues that employees Joint communicate upward and why. Journal of Management Studies, 40(6). https://doi.org/10.1111/1467-6486.00387

Orhancinar, F., \& ZisanDuygu, A. (2013). The Relationship between organizational slience and organizational Citizenship Behavior: A Survey study in the province of Erzurum. Turkey Social and Behavioral Sciences, 99(6).

Paul, W., Alex, B., \& Gomez, R. (2006). The sound of Silence: Which Employers Choose No Employee Voice and Why. Socio- Economic Review, 4(2), 283-299. https://doi.org/10.1093/ser/mw1012

Piderit, S. K., \& Ashford, S. J. (2003). Breaking Silence: Tactical Choice Women Managers Make in Speaking up about Gender -Equity issues. Journal of Management Studies, 40. https://doi.org/10.1111/1467-6486.00388

Rosmary, M. (2003). Organizational discourses: Sounds of silence (3rd ed.). International Critical Management studies conference Lancaster University.

Sahar, N., Hamideh, G., Amerehshojaii, Y., Mahmad, I., \& Seyedmehdi, A. (2013). Study on Relationship between whitener, E.M, Do high commitment human resourse practices affect employee commitment, across - level analysis using hierachial linear modeling. Journal of Management, 27.

Subra, T. (2008, April 16). Employee Silence on critical work issues: podcast organizational Behavior division of the academy of management.

Tutay, M. E. (2010). Receiver design and performance analysis for code-multiplexed transmitted-reference ultra-wideband systems. Doctoral dissertation, bilkent university.

Youssef, G. (2007). Stress Management. The Graduate Studies and Research Development Center, Cairo, Cairo University. 


\section{Appendix. Questionnaire Form}

Dear respondents,

The researchers conduct a study entitled "The Effect of Organizational Silence on Burnout (A Field Study on Workers at Jordanian Five Star Hotels)". Kindly fill in the questionnaire accurately and subjectively, noting that data are only used for scientific research purposes.

Kindly explain the extent of your agreement with each of the following paragraphs by ticking $(\times)$ in front of the answer that matches your opinions:

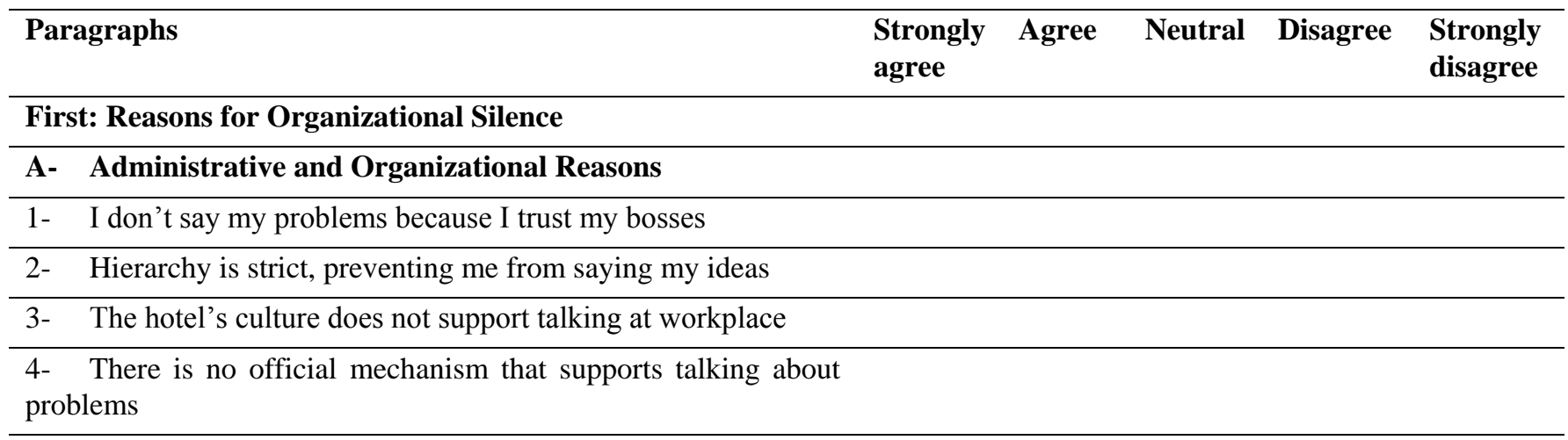

\section{B- Lack of Experience}

1- I don't have sufficient experience to talk about a problem or suggest anything

2- Lack of experience prevents me from talking at work

3- My ideas are not important because of my low job position

4- I don't care about work and workplace problems

\section{C- Concerns related to Work}

1- 1. When I talk about a problem, my current position at work may change

2- I am subjected to abuse and injustice when talking about a problem

3- I hesitate to put any subject for fear of reprisals officials direct

4- Fear of losing my job or position prevents me from speaking

\section{D- Fear of Social Isolation}

1- When I mention a problem, people look at me that I have problems

2- Fear of losing trust and respect for others prevents me from speaking

3- I expect negative feedback from my colleagues and direct officials

4- People who declare problems are not welcomed by others

\section{E- Fear of Damaging Work Relations}

1- Talking about problems can affect my relationship with the others

2- I am afraid that my colleagues will not support me when I talk about a problem 
3- My coworkers may look at me negatively when talking about work problems

4- $\quad$ Fear of losing the satisfaction of officials makes me silent

\section{Second: Burnout}

\section{A- Emotional Exhaustion}

1- I have a feeling that I am emotionally drained because of my work

2- $\quad$ At the end of my daily work, I feel exhausted

3- I feel nervous because of dealing with clients all day long

4- I feel bored and bored because of my work

5- I feel frustrated in my work

\section{B- Depersonalization}

1- I feel indifferent for what happens to my coworkers at work

2- I feel that I treat some clients as numbers

3- I am concerned that this work causes me to be cruel and numb

4- Because of the problems of clients I feel that I am accused

5- Became a harsh person to clients in general since the beginning of this work

\section{C- Low personal accomplishment}

1- 1 - I feel that I have a negative impact on others

2- I do not feel active in my work

3- I do not find myself achieving an important achievement in my work

4- I find myself not dealing efficiently with the problems of clients

5- I do not feel comfortable and happy with my work 